Conclusion This paper will speculate on the implications, for the role of the OHN, of the evolving model of occupational health; from health, environment and safety management, through sickness absence management and vocational rehabilitation, and more recently to the healthy workplace, which extends to a wider workplace health focus, including wellbeing and health risk management in and beyond the work setting.

\section{8b A NORTHERN INSIGHT - THE FUTURE OF OCCUPATIONAL HEALTH SERVICES AND THE ROLE OF OCCUPATIONAL HEALTH NURSING IN FINLAND}

P Österman*. Finnish Association for Occupational Health Nurses, Lääkärikeskus Aava, Helsinki

\subsection{6/oemed-2018-ICOHabstracts. 1017}

Introduction The Global $\mathrm{OH}$ Service development started in 1950's when WHO and ILO formulated a definition of Occupational Health Services and described the fundamental points. The later agreed European Framework Directive doesn't provide obligations to arrange $\mathrm{OH}$ Services and the national legislations still defines the obligations despite the consensus.

Finland is a forerunner with separate legislation for $\mathrm{OH}$ Services since 1978 and later 2001, which obligates employers to arrange $\mathrm{OH}$. The coverage of $\mathrm{OH}$ Services varies greatly in many countries, in Finland it is 92\%. The current number of OHNs in Finland is 2000. Occupational Health2025 - A Strategic Guideline was recently published in Finland. The future challenges of $\mathrm{OH}$ services are supporting work ability and work disability prevention. There still is a great need for $\mathrm{OH}$ Services development despite progress, also in Finland.

Methods Literature Analysis, FAOHN Member Survey 2016

Results The first Finnish OH Act was set in 1978 obligating to arrange preventive $\mathrm{OH}$ services to all employees and many new OHNs were recruited to $\mathrm{OH}$ units. The $\mathrm{OH}$ Decree was set in 1990's to improve the quality of $\mathrm{OH}$ and the maintenance of work ability became a focus. The $\mathrm{OH}$ legislation was renewed in 2001 and $\mathrm{OH}$ Services were redefined to cooperation; starting by defining the $\mathrm{OH}$ needs based on risk assessment and work place survey and planning the actions. The recent Finnish $\mathrm{OH}$ research and follow-up data from Kela shows that $\mathrm{OHNs}$ have bigger role in $\mathrm{OH}$ cooperation than earlier. Most of the workplace surveys, health surveillances and action planning hours are done by the $\mathrm{OH}$ Nurses. The recently published strategic guideline, OH2025 contains three main Objectives

$100 \%$ coverage of $\mathrm{OH}$ services, $\mathrm{OH}$ services for small enterprises and digital OH services. The FAOHN Survey 2016 for OHNs showed a large increase in OHNs' work demands; result and productivity demands.

Conclusion The $\mathrm{OH}$ paradigm is developed from curative to preventive. The role of OHNs is crucial producing cost-effective services for small enterprises. The future $\mathrm{OH}$ challenges in Finland are supporting workers work ability and work disability prevention. The number of educated OHNs is decreasing in Finland and the resources are challenged.

\section{C LEGISLATION OF OCCUPATIONAL HEALTH NURSES}

C Igarashi*. School of Health Sciences, Department of Nursing, Tokyo University of Technology

\subsection{6/oemed-2018-ICOHabstracts.1018}

Introduction In Japan, there were over 30000 suicides per year, from 1997 to 2011. Suicides by working adults accounted for $60 \%$ of the total. The main reason was depression. The Occupational Safety and Health Law was partially revised in December 2015, and workers' stress checks were implemented at workplaces with more than 50 workers. The stress check system is required not only for personal health support but also for group-based analysis to improve ease-ofwork in the workplace environment. It imposes two roles on occupational health nursing professionals: individual support and workplace environment improvement.

Methods Occupational health nurses (1) interview all high stress workers for about $30 \mathrm{~min}$ and extract organisational problems, (2) combine group analysis of stress checks and the results of interviews and (3) communicate the workplaces' problems to management. In workplaces with several high stress people, OHNs advise management to hold workplace meetings in order to discuss how to create a comfortable workplace environment. These are meetings are conducted through the method of Participatory Action-Oriented Training. OHNs also educate managers in creating comfortable work environments.

Results Through the efforts of OHNs, workplace communication has improved and group stress levels have been alleviated. Also, productivity has improved and the number of worker suicides is gradually decreasing.

Conclusion Today, as $75 \%$ of our workers are in the service industry, a major health problem in occupational health is becoming mental health. Therefore, it is important for OHNs to grasp the stress levels of workers and assess stress factors in the workplace. It is occupational health nursing professionals that workers can honestly talk to about their feelings. Moreover, it is important to communicate the stress factors of the workplace to management, in order to improve the workplace environment.

To that end, occupational health nursing professionals need to collaborate to improve service quality, so the Japan Society for Occupational Health has created a system of in-service education based on the occupational health nursing career ladder. Occupational health nursing professionals constantly develop skills that can support health, individuals, groups and organisations.

Utilising stress check leads to comprehensive mental health measures, ultimately leading to a decrease in suicide. In the current Occupational Safety and Health Law, occupational health nursing professionals are positioned as hygiene managers, but since nursing has a large role in health management, 